\title{
COMPATIBILIDAD DEL CONTROL DE CONVENCIONALIDAD CON LA SUPERACIÓN DEL CONTROL DE CONSTITUCIONALIDAD
}

COMENTARIO DE LA SENTENCIA DEL TRIBUNAL SUPERIOR DE JUSTICIA DE CATALUÑA DE 17 DE ENERO 2020, QUE DECLARA LA INAPLICABILIDAD DEL ARTÍCULO 52 d) ET DURANTE EL PERIODO DE VIGENCIA ANTERIOR A SU DEROGACIÓN

\author{
Albert Forcadell Escouffier \\ Abogado en ejercicio y profesor asociado de Derecho del Trabajo y la Seguridad Social \\ en la Universidad Pompeu Fabra, y profesor-consultor de Derecho del Trabajo de la \\ Universidad Oberta de Catalunya

\section{Christian Navarro Díaz} \\ Abogado en ejercicio y profesor de Derecho del Trabajo en la Escuela de Práctica \\ Jurídica del Ilustre Colegio de la Abogacía de Barcelona, y profesor-consultor de \\ Derecho del Trabajo de la Universidad Oberta de Catalunya
}

\begin{abstract}
Comentario de la sentencia del Tribunal Superior de Justicia de Cataluña de 17 de enero 2020, que determina la inaplicabilidad- antes de ser derogado- del artículo 52 d) ET, por el que se establecía como causa válida del despido las ausencias intermitentes en un plazo de dos meses siempre que concurran determinados requisitos. Declaración de improcedencia pese a constatar que en el supuesto analizado concurren todos los requisitos que establecía el artículo 52 d) ET. El Tribunal considera que dicha norma, aunque haya superado recientemente el control de constitucionalidad, no cumple con los estándares superiores de protección que dispensan normas de derecho internacional, (artículos 6.1 del Convenio 158 OIT; artículo 4.1 y 5 del Convenio 155 OIT; artículo 3 de la Carta Social Europea; Artículo 11 del Convenio sobre la eliminación de todas las formas de discriminación contra la mujer de 18/09/1979). Se aplica el control de convencionalidad, manifestación del principio de jerarquía normativa y que forma parte del juicio de aplicabilidad o de selección de la norma aplicable que, a diferencia del juicio de constitucionalidad, corresponde a la jurisdicción ordinaria.
\end{abstract}

Commentary of the Judgement of the Catalan Superior Court of January 17 ${ }^{\text {th }}, 2020$ which determines the inapplicability -before being repealed-of article $52 d$ ) of the Labor Statute (ET). This norm identified intermittent absences at work within a period of two months as a valid cause for dismissal, provided certain requirements were met. The Court considers that, although the norm had recently passed the internal constitutional control, it does not comply with de higher standards of protection 
established by norms of international law (article 6.1 of Convention $n^{\circ} 158$ of the International Labour Organisation; articles 4.1 and 5 of ILO Convention $n^{\circ} 155$; article 3 of the European Social Charter; article 11 of the Convention on the Elimination of All Forms of Discrimination against Women, New York, 18 December 1979.) Conventionality control is applied as manifestation of normative hierarchy and part of the applicability judgment that, unlike the constitutionality judgment, is attributed to the ordinary jurisdiction.

Title: Compatibility of Conventionality and Constitutional Control. Commentary of the Superior Catalonian Court's sentence of January 17 $7^{\text {th }}, 2020$ which determines the inapplicability of article 52 d) of Labour Law (ET) during the period of validity prior to its formal repeal

Palabras clave: Despido por absentismo, aplicación artículo 52 d), principio de jerarquía normativa, control de constitucionalidad, control de convencionalidad.

Keywords: Absenteeism dismissal, article 52 d) application, regulation of normative hierarchy, constitutionality judgment, conventionality judgment.

IUSLabor 1/2020, ISSN 1699-2938, p. 141-156

DOI. 10.31009/IUSLabor.2020.i01.05

Fecha envío: 9.3.2020 | Fecha aceptación: 30.3.2020

\section{Sumario}

1. Introducción

2. Supuesto de Hecho. Concurrencia de los requisitos para extinguir el contrato ex artículo 52 d) ET

3. Cuestión previa. El despido por ausencias justificadas e intermitentes ex artículo 52d) ET ya superó el 'test de constitucionalidad' según el Tribunal Constitucional

4. Compatibilidad del control de constitucionalidad y del control de convencionalidad

5. Control de convencionalidad aplicado al artículo 52 d) ET

6. Comentario crítico. Valoración de la sentencia y potencialidad del control de convencionalidad 


\section{Introducción. Relevancia de la Sentencia}

El intenso debate político y mediático generado en torno al despido por ausencias justificadas intermitentes ex artículo 52 d) ET, así como los hitos jurídicos que han supuesto la Sentencia del Tribunal Constitucional 118/19 de 16 de octubre, que descartó su inconstitucionalidad, por un lado, y su posterior derogación mediante el RD-Ley 4/2020, de 18 de febrero, por otro, pueden determinar que la sentencia que venimos a comentar pase desapercibida. Y es que podría concluirse que, tratándose de una norma que ya ha sido expulsada del ordenamiento jurídico mediante su derogación, la cuestión relativa a su aplicabilidad ya no merece mayor análisis, dado que no va a tener ninguna trascendencia práctica en el futuro.

Ello sería una conclusión precipitada y manifiestamente injusta. La Sentencia 274/2020 de la Sala Social del Tribunal Superior de Justicia de Catalunya, de 17/1/2020, sí supone un hito en sí misma, en tanto que contiene una aplicación sólidamente fundada del denominado "control de convencionalidad" efectuado sobre una norma plenamente constitucional. En base dicho control de convencionalidad se descartará de plano la aplicabilidad del artículo 52.d) ET -un mes antes de ser derogado por el RD-Ley 4/2020, de 18 de febrero-, y ello a pesar de la aparente contradicción que suponía que, dos meses antes de dictarse dicha Sentencia del TSJ de Catalunya, dicho precepto había sido declarado constitucional por el Tribunal Constitucional.

La Sentencia del TSJ de Catalunya expone y razona la distinción entre dicho "control de convencionalidad" y el "control de constitucionalidad". Si éste último se reserva al Tribunal Constitucional, y supone un juicio sobre la adecuación de una determinada norma al contenido esencial y básico de los derechos constitucionales, tal y como han sido identificados y delimitados por la jurisprudencia Constitucional, el "control de convencionalidad" es una operación distinta, que integra el juicio de aplicabilidad, y está atribuido al juez ordinario como un deber exclusivo de la función jurisdiccional por el artículo 6 de la Ley Orgánica del Poder Judicial.

De esta forma, será el juez ordinario a quien corresponderá resolver los conflictos de aplicación entre normas internacionales e internas -siempre que no se entre a valorar en ese juicio su posible colisión con el contenido esencial garantizado la Constitución, función ésta última que queda reservada para el Tribunal Constitucional- $\mathrm{y}$, en consecuencia, corresponderá exclusivamente al juez ordinario la función de seleccionar la norma aplicable con respeto al principio de jerarquía normativa. 
Ejecutando esta operación, la Sentencia del Tribunal Superior de Justicia de Catalunya concluyó que el artículo 52 d) ET, pese a haber sido declarado plenamente constitucional por el Tribunal Constitucional, no era aplicable al caso.

Veamos a continuación este razonamiento.

\section{Supuesto de Hecho. Concurrencia de los requisitos para extinguir el contrato ex artículo 52 d) ET}

Bastará referir aquí que la Sala analiza el caso de una trabajadora con 43 años de antigüedad que es despedida por ausentarse 13 jornadas completas en el plazo de dos meses -tasa de absentismo del 32\%-. La trabajadora acreditó que sus ausencias se debían a problemas médicos -sufría fuertes dolores de espalda y vértigos- sin embargo, sus dolencias no integran la base de excepción que prevé el precepto (enfermedad grave, cáncer, accidente de trabajo, enfermedades vinculadas al embarazo...).

En instancia, el Juzgado Social $n^{\circ} 1$ de Terrassa avaló el despido y declaró la procedencia del mismo, por cuanto se cumplían los requisitos y condicionantes formales y causales establecidos en los artículos 52 d) ET y artículo 53 ET.

En sede suplicación la Sala no cuestionará los hechos declarados probados, ni tampoco cuestionará la subsunción de dichos hechos al supuesto contemplado en el artículo 52 d) ET.

\section{Cuestión previa. El despido por ausencias justificadas e intermitentes ex artículo 52.d) ET ya superó el 'test de constitucionalidad' según el Tribunal Constitucional}

Con carácter previo a la resolución de los motivos del recurso, la Sala se plantea su obligación de resolver sobre la aplicabilidad de la norma, conforme mandata el artículo 6 LOPJ. De hecho, ya no irá más allá, pues tal y como hemos anticipado, al concluir que la norma no es aplicable, resolverá el caso con la declaración de improcedencia por este motivo, ya que de la inaplicabilidad se deriva la ausencia de causa que justifique la extinción contractual.

No obstante, antes de abordar el "control de convencionalidad" y de valorar la aplicabilidad del artículo 52 d) ET, la Sala nos recuerda y reconoce la plena constitucionalidad del precepto, reproduciendo en su propia sentencia los razonamientos en base a los cuales el TC concluyó que el artículo 52 d) ET no era contrario a los derechos a la integridad física -artículo $15 \mathrm{CE}-$, al trabajo -artículo $35.1 \mathrm{CE}-$, y a la 
protección a la salud -artículo $43.1 \mathrm{CE}$-; el órgano promotor $^{1}$ de la cuestión de constitucionalidad había argumentado que dicha regulación de despido objetivo por causa de absentismo podría ser susceptible de condicionar el comportamiento de los trabajadores en perjuicio de sus derechos; pues ante el temor de perder su empleo, el trabajador puede sentirse compelido a acudir a trabajar pese a encontrarse enfermo, asumiendo así un sacrificio en absoluto exigible, que incluso podría complicar la evolución de su enfermedad.

El TC refiere expresamente la sentencia del Tribunal de Justicia de la Unión Europea de 18 de enero de $2018^{2}$ (asunto C-270/16, Ruiz Conejero) en la que se resuelve una cuestión prejudicial sobre la adecuación del artículo 52 d) ET en relación con la interdicción de discriminación por razón de discapacidad derivada de la Directiva 2000/78/CE del Consejo, de 27 de noviembre de 2000, relativa al establecimiento de un marco general para la igualdad de trato en el empleo y la ocupación; y constata que en dicha sentencia se derivaba a la jurisdicción nacional la valoración ponderada de la regulación interna en orden a obtener el fin legítimo, cual es el control del absentismo como manifestación del derecho de libertad de empresa ex artículo 38 CE y 20 ET.

Partiendo de esa finalidad legítima, la Sentencia del TC realizó el obligado juicio de ponderación para resolver el posible conflicto que la tutela de dicha finalidad pudiera plantear en relación con los derechos constitucionales aducidos en la cuestión de

${ }^{1}$ El Juzgado Social $\mathrm{n}^{\circ} 26$ de Barcelona conoció del despido de una trabajadora que se ausentó nueve jornadas completas en dos meses $-22,50 \%$ de las jornadas hábiles- siendo además que sus ausencias superaban el 5\% de las jornadas hábiles en los doce meses anteriores, concretamente el índice era de un $7,74 \%$. Ante ello, y en aras a que la aplicación del artículo 52 d) ET pudiera ser contraria a al derecho, elevó cuestión de inconstitucionalidad ante el TC.

${ }^{2}$ La STJUE de 18/1/18 resuelve la cuestión prejudicial promovida por el Juzgado Social $\mathrm{n}^{\circ} 1$ de Cuenca indicando que "se opone a una normativa nacional que permite al empresario despedir a un trabajador debido a las faltas de asistencia de éste al trabajo, aun justificadas pero intermitentes, cuando tales ausencias sean consecuencia de enfermedades atribuibles a la discapacidad de ese trabajador, salvo que dicha normativa tenga la finalidad legítima de combatir el absentismo y no vaya más allá de lo necesario para alcanzar esa finalidad, lo cual corresponde evaluar al órgano jurisdiccional remitente"

La argumentación del Tribunal la podemos sintetizar en los siguientes razonamientos tal como indica el profesor Beltrán de Heredia en la entrada de su blog de 18 de enero 2018:

i) El artículo 52 d) ET no establece una discriminación directa (se aplica de igual modo a todos los trabajadores)

ii) El artículo 52d) ET "puede desfavorecer a los a los trabajadores con discapacidad y, de este modo, suponer una diferencia de trato indirecta por motivos de discapacidad"

iii) Debe evaluarse esta diferencia de trato en orden a establecer si está objetivamente justificada por una finalidad legítima (combatir el absentismo en las empresas constituye una finalidad legítima) y si los medios aplicados para la consecución de ésta son adecuados y no van más allá de lo necesario para alcanzar la finalidad prevista por el legislador español (a tal efecto el Tribunal establece una batería de elementos que deberá tomar en consideración el juez nacional). 
constitucionalidad. Para ello el Tribunal Constitucional define y delimita el contenido esencial de los derechos a la integridad física (artículo $15 \mathrm{CE}$ ), al trabajo (artículo 35.1 $\mathrm{CE}$ ), y a la protección de la salud (artículo 43.1 CE). Esta determinación por parte del TC del contenido esencial de los derechos constitucionales, y de su extensión, será crucial para el TSJ, que los reproducirá e integrará en su sentencia. Así, una vez determinado el grado de protección que garantiza la Constitución para cada derecho, se podrá valorar y deducir con posterioridad si otras normas internacionales distintas a las derivadas de la Directiva 200/78/CE, dispensan una regulación o protección suplementaria a la que el Tribunal Constitucional ha identificado como contenido esencial garantizado por la Constitución.

En esta operación de valoración del contenido esencial de los derechos constitucionales, y en relación con el derecho a la integridad física (artículo $15 \mathrm{CE}$ ) y protección a la salud (artículo 43.1 CE), el Tribunal Constitucional concluirá que su contenido esencial no se ve afectado por la regulación por despido por absentismo justificado e intermitente ex artículo 52d ET, y ello porque el legislador había tomado en cuenta distintos supuestos de excepción a su aplicación por ausencias debidas a determinadas enfermedades graves, así como porque la regulación legal, en la forma que estaba concebida, no comporta una actuación susceptible de afectar a la salud del trabajador, dado que no suponía situar a las personas en un "peligro grave y cierto para su salud". Ese último inciso es el límite que el TC indica que la regulación del despido ex artículo 52 d) ET no podía traspasar sin vulnerar su contenido esencial del derecho constitucional, concluyendo que, efectivamente, no quedaba traspasado con su redacción vigente al dictar sentencia.

Y en relación con el derecho al trabajo, ex artículo 35.2 CE, el Tribunal Constitucional considera que la regulación del despido por ausencias justificadas e intermitentes tampoco vulnera su contenido esencial, y que en este caso se identifica con i) la necesidad de que la extinción del contrato se funde en una causa objetiva y cierta definida por ley, tal y como efectivamente se considera que acontece con el artículo 52 d) ET; ii) la existencia de una ponderación legal de los intereses en conflicto, como también se considera que hace dicho precepto al prever los supuestos de exclusión y exigencia de requisitos de suficiencia; iii) así como con la posibilidad existente de recurrir judicialmente frente la decisión extintiva $\mathrm{y}$, por último, iv) tener la posibilidad de obtener una compensación adecuada en caso de tratarse de un despido injustificado, siendo que estas dos últimas condiciones también son posibilidades garantizadas por nuestro sistema jurídico de impugnación del despido. 


\section{Introducción del Control de Convencionalidad. Compatibilidad del control de constitucionalidad y del control de convencionalidad}

Sintetizado de esta forma el juicio de constitucionalidad, el Tribunal Superior de Justicia de Catalunya también deja constancia de que el Tribunal Constitucional también quiso expresar su opinión sobre la adecuación del artículo $52 \mathrm{~d}$ ET en relación con el artículo 6.1 del Convenio 158 de la Organización Internacional del Trabajo $(\mathrm{OIT})^{3}$, concluyendo que consideraba que la norma interna no contravenía la norma internacional. En particular, destaca el Tribunal Superior de Justicia que el Tribunal Constitucional descarta dicha contravención del Convenio por considerar que en el apartado segundo del mismo artículo 6 del Convenio 158 OIT se autoriza al legislador interno para introducir limitaciones a la prohibición expresada en el apartado primero, concluyendo que eso es precisamente lo que ha hecho el legislador español al regular el supuesto del artículo 52 d) ET.

No obstante, el Tribunal Superior de Justicia de Catalunya advierte que dichas consideraciones del Tribunal Constitucional constituyen un "obiter dicta" no vinculante, puesto que la valoración de la aplicabilidad de la norma interna no forma parte del control de constitucionalidad, sino del control de convencionalidad, o juicio de aplicabilidad, reservado a la jurisdicción ordinaria.

Y nos recuerda que la primacía de los Tratados y Convenios sobre la ley constitucional interna y, por consiguiente, ese inexcusable deber de la jurisdicción ordinaria de realizar el 'control de convencionalidad', deriva necesariamente de los mandatos contenidos en el artículo 27 de la Convención de Viena de 23/5/694; así como en el artículo 96.1 CE 5 y

\footnotetext{
${ }^{3}$ Convenio $\mathrm{n}^{\mathrm{o}} 158$ sobre la terminación de la relación de trabajo por iniciativa del empleador, adoptado en Ginebra el 22 de junio de 1982. Entrada en vigor en España mediante instrumento de ratificación publicado en el BOE $n^{\circ} 155$ de 29 de junio de 1985 (páginas 20352 a 20354).

El artículo 6 Convenio no 158 OIT reza: "1 La ausencia temporal del trabajo por motivo de enfermedad o lesión no deberá constituir una causa justificada de terminación de la relación de trabajo. 2. La definición de lo que constituye una ausencia temporal del trabajo, la medida en que se exigirá un certificado médico y las posibles limitaciones a la aplicación del párrafo 1 del presente artículo serán determinadas de conformidad con los métodos de aplicación mencionados en el artículo 1 del presente Convenio".

${ }^{4}$ Artículo 26 Convención de Viena: "El derecho interno y la observancia de los tratados. Una parte no podrá invocar las disposiciones de su derecho interno como justificación del incumplimiento de un tratado. Esta norma se entenderá sin perjuicio de lo dispuesto en el artículo 46."

5 Artículo 96.1 CE: “Los tratados internacionales válidamente celebrados, una vez publicados oficialmente en España, formarán parte del ordenamiento interno. Sus disposiciones sólo podrán ser derogadas, modificadas o suspendidas en la forma prevista en los propios tratados o de acuerdo con las normas generales del Derecho internacional."
} 
en la Ley 25/2014, de 27 de noviembre, de Tratados y otros Acuerdos internacionales ${ }^{6}$, que desarrolla dicho precepto constitucional.

De hecho, esta concepción sobre la compatibilidad del control de constitucionalidad y el control de convencionalidad, así como la consideración de "obiter dicta" que tendrán los pronunciamientos que pueda hacer el Tribunal Constitucional en relación con el juicio de aplicabilidad de normas internas en base a su adecuación a preceptos jerárquicamente superiores del ordenamiento jurídico internacional, ha sido asentada y confirmada por el propio Tribunal Constitucional en sus sentencias 118/19 ${ }^{7}$ y $140 / 2018^{8}$, cuyo texto reproducimos al pie de página por su claridad y contundencia al respecto.

\footnotetext{
${ }^{6}$ Ley 25/2014, de 27 de noviembre:

Artículo 28 Eficacia.1. Las disposiciones de los tratados internacionales válidamente celebrados solo podrán ser derogadas, modificadas o suspendidas en la forma prevista en los propios tratados o de acuerdo con las normas generales de Derecho Internacional. 2. Los tratados internacionales válidamente celebrados y publicados oficialmente producirán efectos en España desde la fecha que el tratado determine o, en su defecto, a partir de la fecha de su entrada en vigor.

Artículo 29. Observancia. Todos los poderes públicos, órganos y organismos del Estado deberán respetar las obligaciones de los tratados internacionales en vigor en los que España sea parte y velar por el adecuado cumplimiento de dichos tratados.

Artículo 30. Ejecución.1. Los tratados internacionales serán de aplicación directa, a menos que de su texto se desprenda que dicha aplicación queda condicionada a la aprobación de las leyes o disposiciones reglamentarias pertinentes

Artículo 31. Prevalencia de los tratados. Las normas jurídicas contenidas en los tratados internacionales válidamente celebrados y publicados oficialmente prevalecerán sobre cualquier otra norma del ordenamiento interno en caso de conflicto con ellas, salvo las normas de rango constitucional.

${ }^{7}$ Sentencia Tribunal Constitucional $n^{\circ} 118 / 19$, de 16 de octubre, (BOE $n^{\circ} 279$, de 20 de octubre de 2019), Cuestión de inconstitucionalidad 2960-2019: "Por lo que se refiere a la presunta contradicción del art 52 d) LET con el artículo 6.1 del Convenio 158 de la OIT que apunta el auto de planteamiento, procede recordar una vez más que los tratados internacionales no integran el canon de constitucionalidad bajo el que hayan de examinarse las leyes internas, al margen de su valor hermenéutico ex artículo 10.2 CE en el caso de los textos internacionales sobre derechos humanos (por todas, SSTC 49/1988, de 22 de marzo, FJ 14; 28/1991, de 14 de febrero, FJ 5; 254/1993, de 20 de julio, FJ 5; 235/2000, de 5 de octubre, FJ 11; 12/2008, de 29 de enero, FJ 2, y 140/2018, de 20 de diciembre, FJ 6). La eventual contradicción entre la regulación interna y los convenios y tratados internacionales ratificados por España no determina por sí misma violación constitucional alguna; se trata de un juicio de aplicabilidad control de convencionalidad- que pertenece al ámbito de la legalidad ordinaria".

${ }^{8}$ Sentencia Tribunal Constitucional $\mathrm{n}^{\circ}$ 140/2018, de 20 de diciembre, (BOE $\mathrm{n}^{\circ} 22$, de 25 de enero de 2019), Recurso de inconstitucionalidad $\mathrm{n}^{\circ}$ 3754-2014 "el análisis de convencionalidad que tiene cabida en nuestro ordenamiento constitucional no es un juicio de validez de la norma interna o de constitucionalidad mediata de la misma, sino un mero juicio de aplicabilidad de disposiciones normativas; de selección de derecho, aplicable, que queda, en principio, extramuros de las competencias del Tribunal Constitucional que podrá, no obstante, y en todo caso por la vía procesal que se pone a su alcance a través del recurso de amparo constitucional, revisar la selección del derecho formulada por los jueces ordinarios en determinadas circunstancias bajo el parámetro del artículo 24.1 CE, que
} 
De ello se extrae que es perfectamente posible y, de hecho, obligado, que el juzgador ordinario deje de aplicar una norma interna, pese a haber sido declarada acorde con la Constitución, si la considera contraria al principio de jerarquía normativa por no adecuarse a los Tratados y Convenios internacionales ratificados por España, habida cuenta del indudable carácter monista que tiene nuestro sistema de recepción del derecho internacional.

\section{Control de convencionalidad aplicado al artículo 52 d) ET}

Tras citar el marco normativo internacional regulador de los derechos a no ser despedido sin justa causa, (Convenio 158 OIT, Carta Social Europea), el derecho a la prevención de riesgos laborales, (Convenio 155 OIT y Carta Social Europea) y la prohibición de discriminación por razón de género, (Convención sobre eliminación de todas las formas de discriminación contra la mujer), así como la doctrina de órganos consultivos o jurisdiccionales como la Comisión de Expertos en Aplicación de Recomendaciones de la OIT (CEAR), el Comité Europeo de Derechos Sociales (CEDS), o del Tribunal Europeo de Derechos Humanos (TEDH); la Sala de lo Social del Tribunal Superior de Justicia de Catalunya detecta y concluye que el artículo 52 d) ET es contrario a diversos artículos contenidos en dichas normativa internacional, cuya aplicación debe prevalecer en detrimento de la norma interna.

En cuanto al derecho a no ser despedido sin justa causa, se concluye que, si bien el artículo 52 d) ET no vulnera el artículo $35 \mathrm{CE}$, en tanto que el contenido esencial de este derecho constitucional se concretó en el derecho a no ser despedido sin justa causa identificada objetivamente por la ley, en la obligación de que el legislador pondere intereses, y en poder reaccionar frente al despido y obtener una compensación; sí que contraviene el artículo 6.1 del Convenio 158 OIT, toda vez que dicho precepto proscribe clara y expresamente que la ausencia temporal por enfermedad pueda constituir una causa justa de despido. De esta forma, el contenido convencional del derecho ofrece un estándar de protección más elevado que la que garantiza la norma interna y el artículo $35 \mathrm{CE}$ y, en consecuencia, debe prevalecer frente a la misma. En relación con el óbice que pudiera suponer la habilitación que hace el apartado segundo del mismo artículo 6 del Convenio 158, que autoriza al establecimiento de limitaciones por medio de la legislación nacional, la sentencia razona de forma contundente que tales limitaciones no pueden suponer una derogación de facto de prohibición que establece el apartado

garantiza "que el fundamento de la decisión judicial sea la aplicación no arbitraria ni irrazonable de las normas que se consideren adecuadas al caso, pues tanto si la aplicación de la legalidad es fruto de un error patente con relevancia constitucional, como si fuere arbitraría, manifiestamente irrazonada o irrazonable no podría considerarse fundada en Derecho, dado que la aplicación de la legalidad sería tan sólo una mera · apariencia". 
primero, de forma que a través de dicho procedimiento se deje sin efecto el compromiso internacional adquirido por el Estado, y a tal efecto se citan dictámenes del $\mathrm{CEACR}^{9}$ y del CEDS $^{10}$ que apuntan en tal sentido.

De forma similar, en relación al derecho a la prevención frente de riesgos laborales, la Sentencia razona que los artículos 4 y 5 del Convenio 155 de la OIT $^{11}$ dispensan una protección suplementaria o más reforzada que aquella que el Tribunal Constitucional ha concluido que garantizan el contenido esencial de los artículos 15 y $43.1 \mathrm{CE}$. Al respecto, el TSJ constata que el Tribunal Constitucional no descarta que el artículo $52 \mathrm{~d}$ ) ET suponga un riesgo para la salud, pero ha concluido que dicha regulación es asumible desde la perspectiva constitucional, al haberse hecho una ponderación de intereses inherentes a dichos derechos a la integridad física y protección de la salud, en relación con los protegidos por el artículo $38 \mathrm{CE}$ (Libertad de Empresa), concluyendo que como dicho riesgo no es grave o inminente, por este motivo no entra en la tutela constitucional. En cambio, los artículos 4 y 5 del Convenio 155 OIT y artículo $3 \mathrm{CSE}^{12}$ establecen obligaciones de prevención y protección frente a todo tipo de riesgos, y no meramente frente a los graves e inminentes, y en la ponderación de intereses, como la libertad de empresa o la productividad, imponen a los estados la reducción al mínimo de

\footnotetext{
${ }^{9}$ Informe de la Comisión de Expertos en Aplicación de Convenios y Recomendaciones de la OIT (CEACR) librado ante la Conferencia Internacional del Trabajo 82 $2^{\mathrm{a}}$ Reunión de 1995, que interpreta el artículo 6 del Convenio 158 OIT del siguiente modo: "El Convenio deja que el concepto de ausencia temporal se defina en las disposiciones nacionales. Pero, a entender de la Comisión, si la ausencia se define sobre la base de la duración, se la debería prever de modo tal que siga siendo compatible con el objetivo del artículo, que consiste en proteger el empleo del trabajador en un momento en que éste se encuentre en la imposibilidad de cumplir con sus obligaciones por razones de fuerza mayor".

${ }^{10}$ El Comité Europeo de Derechos Sociales (CEDS) ha interpretado el artículo 24.3 f) CSE revisada de 3/5/1996, firmada por España y en vía de ratificación, que establece que no se consideran justas causas de despido "La ausencia temporal del trabajo debido a enfermedad o lesión" (Conclusiones 2012, Turquía. Vid. Digesto de jurisprudencia del Comité Europeo de Derechos Sociales. Diciembre 2018, p.203-205).

${ }^{11}$ Artículo 4 Convenio n 155 OIT: "1. Todo Miembro deberá, en consulta con las organizaciones más representativas de empleadores y de trabajadores interesadas y habida cuenta de las condiciones y práctica nacionales, formular, poner en práctica y reexaminar periódicamente una política nacional coherente en materia de seguridad y salud de los trabajadores y medio ambiente de trabajo. 2. Esta política tendrá por objeto prevenir los accidentes y los daños para la salud que sean consecuencia del trabajo, guarden relación con la actividad laboral o sobrevengan durante el trabajo, reduciendo al mínimo, en la medida en que sea razonable y factible, las causas de los riesgos inherentes al medio ambiente de trabajo".

12 Artículo 3 de la Carta Social Europea: "Derecho a la seguridad e higiene en el trabajo. Para garantizar el ejercicio efectivo del derecho a la seguridad e higiene en el trabajo, las Partes Contratantes se comprometen: 1) a formular, aplicar y revisar periódicamente una política nacional coherente sobre seguridad e higiene en el trabajo y sobre el entorno de trabajo. Esta política tendrá como objeto principal la mejora de la seguridad y la higiene en el trabajo y la prevención de accidentes y de daños a la salud derivados o relacionados con el trabajo o que se produzcan en el curso del mismo, en particular minimizando las causas de los riesgos inherentes al entorno de trabajo".
} 
las causas que generan estos tipos de riesgos. Así, dado el efecto de presentismo que legítimamente pretende incentivar el artículo 52 d) ET, fácil es concluir que propicia la reincorporación al trabajo de personas enfermas antes de su curación, o bien previene que cause baja por incapacidad temporal, siendo evidente que ello genera un riesgo, aunque no sea grave, para su salud, y para los de terceros (por ejemplo, ante el riesgo de contagio de enfermedades contagiosas como podría ser el coronavirus - covid19, que se está convirtiendo en pandemia mientras se escribía este artículo, y que bien podría haber motivado que un trabajador no causara baja si temiera que por ello podía ser despedido).

Por último, mención aparte merece la contradicción apreciada en relación con el artículo 11 de la Convención sobre eliminación de todas las formas de discriminación contra la mujer hecha en Nueva York el 18 de diciembre de $1979^{13}$. El TSJ subraya que esta perspectiva de género, salvo por el voto particular de la Magistrada María Luisa Balaguer Callejón, no fue abordada por la STC 118/2019, puesto que el TC se limitó a valorar la adecuación del artículo 52 d) ET a los preceptos aducidos en la cuestión de constitucionalidad (artículos 15, 35.1, y 43.1 CE).

Entiende el Tribunal Superior de Justicia que al ejercer el control de convencionalidad está, no sólo habilitado, sino obligado y no puede eludir, incorporar la perspectiva de género, y ello por cuanto así lo impone el artículo 4 de la LO 3/2017 que establece que la Igualdad se integrará y observará en la interpretación y aplicación de las normas jurídicas. Así las cosas, el TSJ razona y concluye que el artículo 52 d) ET entraña un supuesto de discriminación indirecta, por cuanto, pese a su caracterización aparentemente neutra, tiene un impacto más perjudicial para el género femenino, señalando a tal efecto las estadísticas del INSS sobre procesos de baja segregados por sexos.

La dificultad que observamos en la aportación de esta última argumentación, cuyo fondo y apreciación compartimos plenamente, es que, a diferencia de lo que acontece

\footnotetext{
${ }^{13}$ Artículo 11 Convención sobre eliminación de todas las formas de discriminación contra la mujer (BOE de 16 de diciembre 1983): "1. Los Estados Partes adoptarán todas las medidas apropiadas para eliminar la discriminación contra la mujer en la esfera del empleo a fin de asegurar a la mujer, en condiciones de igualdad con los hombres, los mismos derechos, en particular: (...)

b) El derecho a las mismas oportunidades de empleo, inclusive a la aplicación de los mismos criterios de selección en cuestiones de empleo;

c) El derecho a elegir libremente profesión y empleo, el derecho al ascenso, a la estabilidad en el empleo y a todas las prestaciones y otras condiciones de servicio, y el derecho a la formación profesional y al readiestramiento, incluido el aprendizaje, la formación profesional superior y el adiestramiento periódico; (...)

f) El derecho a la protección de la salud y a la seguridad en las condiciones de trabajo, incluso la salvaguardia de la función de reproducción."
} 
con el derecho a no ser despedido sin justa causa, y con el derecho a protección de riesgos laborales, en relación con este derecho no se razona en qué medida la norma internacional ofrece un estándar de protección más alto o distinto del que ofrece la norma interna y/o garantiza la Constitución. No queremos decir con ello que no tenga fundamento la declaración de inaplicabilidad del precepto, puesto que en definitiva lo encuentra en la omisión de pronunciamiento del Tribunal Constitucional sobre esta perspectiva, así como en el mandato expreso e ineludible que hace el artículo 4 de la LOI 3/2017 que, en definitiva, también se refiere a la aplicación de la norma y, por tanto, a la operación de selección de las mismas para el caso. Lo que venimos a subrayar $\mathrm{u}$ observar, en primer término, es que el fundamento es distinto a los dos casos anteriores y, por tanto, por dos vías distintas se llega a la inaplicación de la norma.

En segundo término, al fundarse en la misma protección que ofrece la constitución para un derecho fundamental de los previstos entre el artículo 14 y $29 \mathrm{CE}$, en este caso, el contenido del Principio de No Discriminación, vemos que es cuestionable que no se declare la nulidad del despido, en lugar de la improcedencia, pues así lo impondría el mandato contenido en el artículo 55.5 ET. El TSJ salva esta cuestión afirmando que detecta la infracción en el control de convencionalidad, descartando directamente la aplicación del artículo 52 d) ET, "sin entrar en el juicio de constitucionalidad."

\section{Comentario crítico. Valoración de la sentencia y potencialidad del control de convencionalidad}

El control de convencionalidad, tal y como ha sido explicado y ejercitado por el Tribunal Superior de Justicia de Catalunya en la sentencia que acabamos de comentar, se revela como una herramienta que, de ser utilizada por los jueces y tribunales del orden social, debería poner en cuestión algunos aspectos de nuestro sistema jurídico laboral y, muy en particular, la aplicabilidad de determinadas normas internas relativas al sistema de protección frente al despido, máxime en un contexto de intensa degradación de dicho sistema de protección, fruto de sucesivas reformas laborales que lo han llevado a extremos que, a nuestro juicio, nos permiten afirmar que en determinados aspectos el derecho laboral ha perdido el carácter tuitivo o protector que debía dispensar frente al derecho común. Y es que con la sucesiva desaparición de las garantías y la progresiva disminución de la protección que dispensaba la normativa interna, lo lógico es que adquieran relevancia, visibilidad y en suma, aplicabilidad, normas de derecho internacional que tradicionalmente eran ignoradas o infravaloradas, al ser consideradas como mínimos que siempre eran superados por el ordenamiento jurídico interno de un autoproclamado Estado Social. 
En esta materia relativa a la protección frente al despido, destaca el Convenio $\mathrm{n}^{\mathrm{o}} 158$ OIT, así como la Carta Social Europea revisada de 1996, en trámite de ratificación. Ambos textos, casi idénticos en la regulación que brindan, contienen normas potentes y claras, con mandatos expresos o imperativos, y no supeditados a ulteriores desarrollos legislativos, de los que se tendrían que derivar consecuencias y efectos jurídicos si se aprecia judicialmente su aplicabilidad directa que, ya hemos visto, es obligada para los poderes públicos del Estado.

Y es que cada vez resulta más evidente el contraste entre nuestras normas internas, progresivamente degradadas, y las normas internacionales que, entre otras cuestiones, proscriben imperativamente el despido acausal (artículo 4 Convenio 158 OIT), prohíben el despido sin determinadas garantías formales que nuestro ordenamiento no recoge (artículo 7), imponen un juicio de suficiencia y racionalidad en relación con la valoración de las causas de despido, (artículos 8 y 9) y, finalmente, y sin ánimo exhaustivo, imponen la necesidad de establecer compensaciones adecuadas que nuestro ordenamiento no recoge, incluyendo la calificación de nulidad u obligación de readmitir a supuestos no contemplados en el artículo 55.5 ET, y que se correspondan con la intensidad y realidad de ese ilícito o perjuicio (artículo 10).

Así, por ejemplo, nos atrevemos a apuntar que tal vez cabría revisar jurisprudencia ya antigua que estimó que el artículo 7 del Convenio 158 de la OIT no es de directa aplicación, cuando dicho precepto establece una prohibición imperativa de "dar por terminado el contrato antes de ofrecerle al trabajador la posibilidad de defenderse de los cargos formulados contra él, a menos que no pueda pedirse razonablemente al empleador que le conceda esta posibilidad". Como es fácil observar, dicho precepto no se corresponde con nuestra normativa interna que limita esa garantía solo a representantes de los trabajadores, o a sectores o empresas que tienen esa protección establecida en convenio colectivo. Por otro lado, si se mantiene esa jurisprudencia que defiende que dicha garantía de audiencia ya viene cubierta por la posibilidad de recurrir frente al despido, mal podrá sostenerse una regulación como la vigente en la que se pretende dar efectos constitutivos "ex tunc" a la decisión extintiva en los supuestos de opción empresarial por la extinción, sin condena a salarios de tramitación ni recomposición de la relación laboral, puesto que de ese modo se estaría dando por terminada la relación "antes" de que pudiera verificarse el derecho de defensa que el Tribunal Supremo identifica como la garantía prevista en el artículo 7 del Convenio 158 OIT.

Cabría igualmente revisar la aplicabilidad del sistema de calificaciones previsto en el artículo 55 ET -que concibe los supuestos de nulidad como un "númerus clausus"- a los supuestos de extinción prohibidos imperativamente por el artículo 4 del precitado 
Convenio $158 \mathrm{OIT}^{14}$, como es el despido sin causa, o el desistimiento empresarial. Para estos supuestos de cualificada injustificación o ilicitud del despido consideramos imperativa la calificación de nulidad civil prevista en el artículo $6.3 \mathrm{CC}$, que debe distinguirse de la aplicación del fraude de ley ex artículo 6.4 CC. (Establece dicho artículo 6.3.CC: "Los actos contrarios a las normas imperativas y a las prohibitivas son nulos de pleno derecho, salvo que en ellas se establezca un efecto distinto para el caso de contravención"). Entendemos que esa nulidad debería ser, y no otra, la sanción a una modalidad de extinción no prevista en el artículo 49 ET, y a la que, por tanto, no se debería aplicar el sistema de calificaciones del artículo 55 ET, reservadas a los supuestos de extinción que sí están regulados en el Estatuto de los Trabajadores. (No cabe aducir aquí que las normas procesales de impugnación y calificación del despido disciplinario son comunes para todo tipo de despido, pues el apartado tercero del artículo 103 LRJS se cuida de establecer que, si bien se seguirá la misma modalidad procesal para la impugnación de todas las decisiones extintivas, ello se hará sin perjuicio de las consecuencias sustantivas de cada tipo de extinción contractual, siendo que la regulación de las calificaciones del despido y las compensaciones, pese a hallarse en la LRJS, son normas de carácter sustantivo, tal y como se desprende de que también estén contempladas en el estatuto de los trabajadores.) Por lo demás, el recurso a dicha calificación de nulidad viene expresamente autorizada por el tenor literal del artículo 10 del Convenio $158 \mathrm{OIT}^{15}$, en la medida en que debe considerarse que el juzgador sí está facultado para imponer la restitución en el puesto de trabajo, (artículo 6.3 del Código Civil).

Y aún otras cuestiones de mayor calado, y que desbordan el objeto de este artículo, pueden y deben ser analizadas a la luz del Convenio 158 OIT y la Carta Social Europea (versión revisada, 1996, en vías de ratificación). En particular, cabe preguntarse hasta qué punto es jurídicamente homologable con un sedicente Estado Social y Derecho, una regulación de las compensaciones frente al despido que equipara como equivalente el remedio de la readmisión del trabajador con el remedio de la indemnización, pero que establece el derecho a salarios de tramitación sólo para el supuesto en que la parte que ha cometido el ilícito escoja la opción que más le conviene, y ello mientras se proclama

\footnotetext{
${ }^{14}$ Artículo 4 Convenio n ${ }^{\circ} 158$ OIT: "No se pondrá término a la relación de trabajo de un trabajador a menos que exista para ello una causa justificada relacionada con su capacidad o su conducta o basada en las necesidades de funcionamiento de la empresa, establecimiento o servicio".

${ }^{15}$ Artículo 10 Convenio $\mathrm{n}^{\circ} 158$ OIT: "Si los organismos mencionados en el artículo 8 del presente Convenio llegan a la conclusión de que la terminación de la relación de trabajo es injustificada y si en virtud de la legislación y la práctica nacionales no estuvieran facultados o no consideraran posible, dadas las circunstancias, anular la terminación y eventualmente ordenar o proponer la readmisión del trabajador, tendrán la facultad de ordenar el pago de una indemnización adecuada u otra reparación que se considere apropiada."
} 
como fundamento de nuestro sistema de derecho laboral y constitucional la promoción de la conservación y estabilidad en el empleo.

En fin, igualmente inconsistente y alejado del criterio de "adecuación", en el sentido que exigen tanto el artículo 10 del Convenio 158 OIT, como el artículo 24 de la Carta Social Europea, se perfila un sistema de indemnizaciones tasadas, con desentendimiento del daño real causado, y así ya ha empezado a ser apreciado en el ámbito internacional, como ha sucedido en los casos analizados por el Comité Europeo de Derechos Sociales en sus decisiones adoptadas en fecha 6/9/2016 (caso Finnish Society of Social Rights contra Finlandia), o más recientemente en fecha 10/10/2019 (caso Confederazione Italiana del Lavoro CGIL contra Italia).

De ahí que observemos como lógico y necesario que los jueces y tribunales del orden social recurran, cada vez con mayor frecuencia, a las normas de derecho internacional para fundar sus sentencias, aplicándolas en detrimento de las normas internas. De hecho, tal y como razona la sentencia comentada, es obligación de todo juzgador integrar el control de convencionalidad en el proceso de selección de la norma aplicable. En contraste, de no ser abordados o subsanados los "déficits" que el control de convencionalidad patentiza, se potencia la degradación técnico-jurídica de la jurisdicción social, condenándola a incurrir en situaciones de extrema hipocresía, como es defender en el plano teórico la causalidad del despido que supuestamente consagraría nuestro ordenamiento jurídico, frente a una práctica y una tendencia legislativa y judicial que en determinados momentos tiende a concebir el sistema de extinción del contrato de trabajo como un sistema de despido libre o "at will", al que se impone un precio tasado y exento de valoración de correspondencia con la intensidad y/o gravedad de los supuestos actos ilícitos del infractor.

Por este motivo, celebramos la existencia de Sentencias como la que hemos tenido el privilegio de analizar en este artículo. Como bien dice el profesor Antonio Baylos en su $\operatorname{blog}^{16}$ es valiosa y valiente. Incluso nos atrevemos a calificarla de revolucionaria en cuanto a la potencia de su argumentación y metodología, si bien es cierto que el control de convencionalidad ha sido apuntado por anteriores sentencias, e incluso ejercitado por algún Juzgado de lo Social. Lástima que, como bien sabe el lector que ha concluido este artículo, lo cual agradecemos, los efectos o consecuencias van a ser escasos o inexistentes en relación con el despido por ausencias ex artículo 52 d) ET, pues la sentencia se ha dictado pocas semanas antes de la derogación de este precepto que llevaba decenios en vigor. No obstante, constatamos que su valor es elevado si se toma

16 ¿Debe ser declarado improcedente el despido por enfermedad tras la derogación del del artículo 52 d) del Estatuto de los Trabajadores? Entrada de 24 de febrero de 2020. https://baylos.blogspot.com/2020/02/debe-ser-declarado-improcedente-el.html 
en consideración que el modo en que se realiza el control de convencionalidad, trasladable a otras regulaciones vigentes, puede contribuir a racionalizar nuestro sistema jurídico de protección frente al despido. 